Check for updates

Cite this: J. Mater. Chem. C, 2018, 6, 11731

Received 19th February 2018 Accepted 10th October 2018

DOI: $10.1039 / \mathrm{c} 8 \mathrm{tc} 00859 \mathrm{k}$

rsc.li/materials-c

\section{Direct and continuous hydrothermal flow synthesis of thermochromic phase pure monoclinic $\mathrm{VO}_{2}$ nanoparticles $\dagger$}

\author{
Delphine Malarde, (D) $\ddagger^{a}$ Ian D. Johnson, (D) $\ddagger^{a}$ Ian J. Godfrey, (D) \\ Michael J. Powell, (D) a Giannantonio Cibin, (D) ${ }^{\mathrm{b}}$ Raul Quesada-Cabrera, ${ }^{\mathrm{a}}$ \\ Jawwad A. Darr, (D) ${ }^{a}$ Claire J. Carmalt, (D) ${ }^{a}$ Gopinathan Sankar, ${ }^{a}$ Ivan P. Parkin (D) ${ }^{a}$ \\ and Robert G. Palgrave $\mathbb{D}$ *a
}

\begin{abstract}
Monoclinic vanadium(IV) oxide $\left[\mathrm{VO}_{2}(\mathrm{M})\right]$ is a widely studied material due to its thermochromic properties and its potential use in energy-efficient glazing applications. $\mathrm{VO}_{2}(\mathrm{M})$ nanoparticles can be a great advantage for energy-efficient glazing as below $50 \mathrm{~nm}$ the nanoparticles poorly interact with visible wavelengths - resulting in an increase in visible light transmittance whilst maintaining the thermochromic response of the material. The direct synthesis of $\mathrm{VO}_{2}(\mathrm{M})$ nanoparticles with effective thermochromic properties will be a step forward towards industrial applications of this material. Unfortunately, many of the synthesis processes reported so far involve multiple steps, including post-treatment, and the synthesis is not always reproducible. In this study, we present the first direct synthesis of pure monoclinic $\mathrm{VO}_{2}$ nanoparticles by continuous hydrothermal flow synthesis (CHFS). TEM images showed that nanoparticles in the size range of 30-40 nm were produced. The $\mathrm{VO}_{2}(\mathrm{M})$ nanoparticles also showed good thermochromic properties with a solar modulation $\left(\Delta T_{\text {sol }}\right)$ of $3.8 \%$, as established by UV/Vis spectroscopy. $A$ range of analytical methods was used to characterise the materials, including $X$-ray absorption spectroscopy (XANES and EXAFS), X-ray diffraction (XRD), X-ray photoelectron spectroscopy (XPS) and transmission electron microscopy (TEM). The influence of niobium ( $\mathrm{Nb}$ ) doping on the physical and thermochromic properties of the $\mathrm{VO}_{2}$ nanoparticles was also explored. Previous work has shown a sharp metal-tosemiconductor transition of $\mathrm{VO}_{2}$ upon incorporation of a $\mathrm{Nb}$ dopant. The results of the current work suggested that these changes are likely due to changes on the local structure of the oxide.
\end{abstract}

\section{Introduction}

The numerous crystal structures and phase transitions of vanadium(Iv) oxide $\left(\mathrm{VO}_{2}\right)$ make it a promising material for a wide range of applications including batteries, ${ }^{1,2}$ gas sensors ${ }^{3}$ and solar control coatings for smart windows. ${ }^{4,5}$ The monoclinic form of vanadium dioxide, $\mathrm{VO}_{2}(\mathrm{M})$ (space group $P 121 / c 1$ ) has attracted great interest due to its thermochromic properties. $\mathrm{VO}_{2}(\mathrm{M})$ has the ability to reversibly transform from the semiconducting monoclinic phase $\mathrm{VO}_{2}(\mathrm{M})$ to the semi-metallic rutile phase $\mathrm{VO}_{2}(\mathrm{R})$ (space group $P 42 / \mathrm{mnm}$ ). ${ }^{6}$ The reversible metal-to-semiconductor transition (MST) occurs at ca. $68{ }^{\circ} \mathrm{C}$ for

\footnotetext{
${ }^{a}$ Department of Chemistry, Materials Chemistry Centre, University College London, 20 Gordon Street, London WC1H OAJ, UK. E-mail: r.palgrave@ucl.ac.uk

${ }^{b}$ Diamond Light Source Ltd, Diamond House Harwell Science and Innovation Campus Didcot, Oxfordshire OX11 ODE, UK

$\dagger$ Electronic supplementary information (ESI) available. See DOI: 10.1039/ c8tc00859k

\$ These authors contributed equally.
}

a typical undoped $\mathrm{VO}_{2}$ material. ${ }^{7}$ When heated beyond this temperature, the material's optical properties change drastically - from highly transmissive to highly reflective - in the NIR region, and its electrical conductivity increases by several orders of magnitude. ${ }^{8}$ The thermochromic properties of $\mathrm{VO}_{2}(\mathrm{M})$ and its relatively low temperature transition, i.e. close to room temperature, make it an interesting material for energy-efficient glazing applications.

The strong absorption of $\mathrm{VO}_{2}(\mathrm{M})$, however, as well as its high reflectivity due to its narrow band gap has a negative impact on both visible light transmittance $\left(T_{\text {lum }}\right)$ and solar modulation $\left(\Delta T_{\text {sol }}\right)$ - two essential parameters for measuring the energy saving efficiency of glazing. $T_{\text {lum }}$ indicates the percentage of visible light passing through the coated glass while $\Delta T_{\text {sol }}$ represents the ability of the coating to modulate the solar energy. It had been quite challenging to optimize both parameters as the increase of $T_{\text {lum }}$ often induces a reduction of $\Delta T_{\mathrm{sol}}$, and vice versa.

Li et al. ${ }^{9,10}$ showed that both parameters $T_{\text {lum }}$ and $\Delta T_{\text {sol }}$ could be significantly improved simultaneously by embedding 
$\mathrm{VO}_{2}$ nanoparticles in a host material rather than synthesising a continuous $\mathrm{VO}_{2}$ film. It has been established, for example, that a $5 \mu \mathrm{m}$ thick film of 1 vol\% of well-dispersed $\mathrm{VO}_{2}$ nanoparticles shows higher $T_{\text {lum }}$ and $\Delta T_{\text {sol }}$ values compared to an equivalent continuous $\mathrm{VO}_{2}$ film with a thickness of $50 \mathrm{~nm} .{ }^{11}$ In addition, it has been demonstrated that $\mathrm{VO}_{2}$ nanoparticles of $c a .50 \mathrm{~nm}$ (or less) weakly interact with visible light while those with particle sizes of $c a .20 \mathrm{~nm}$ or less suppress optical scattering. ${ }^{4,12}$ Hence, it is important to tailor particle sizes and dispersion thereof.

The direct synthesis of $\mathrm{VO}_{2}(\mathrm{M})$ nanoparticles can be challenging due to the multiple valence states of the vanadium ion and the ease of oxidation/reduction of $\mathrm{V}^{4+}$ to $\mathrm{V}^{5+} / \mathrm{V}^{3+}$ species. The synthesis of phase pure monoclinic $\mathrm{VO}_{2}$ can require several steps including post-synthesis heat-treatment. Any additional processing of the material risks oxidation or reduction of the vanadium, reducing or destroying the functionality. Hydrothermal synthesis is a common route to obtain $\mathrm{VO}_{2}(\mathrm{M})$ nanoparticles, however, this method typically requires 24 to 48 hours to produce phase pure $\mathrm{VO}_{2}(\mathrm{M})$ nanoparticles in a batch process and it is hardly reproducible. ${ }^{13,14}$

Continuous hydrothermal flow synthesis (CHFS) is a method used to produce nanoparticles. CHFS has the advantage of being a direct, reproducible and scalable method. ${ }^{15}$ Unlike batch hydrothermal processes, CHFS is a continuous process, thus once a system is optimised it is possible to produce $\mathrm{kg}$ of material per hour. In CHFS, a stream of supercritical water is mixed with an ambient temperature stream of metal precursor salts (in an engineered mixer) to almost instantly form nanoparticles in a good yield (typically above $85 \%)$. In this process, metal oxide nanoparticles are produced very rapidly by the hydrolysis and subsequent dehydration (or degradation) of the metal salts. ${ }^{16,17}$ Previously, CHFS has been utilised to prepare $\mathrm{VO}_{2}(\mathrm{M})$ and $\mathrm{Nb}$-doped $\mathrm{VO}_{2}(\mathrm{M})$ samples in a two-step process, where the initial $\mathrm{VO}_{2}$ product contained impurities and required post-synthesis annealing at $600{ }^{\circ} \mathrm{C}$ to obtain phase pure $\mathrm{VO}_{2}(\mathrm{M}) .^{1,18,19}$ This was synthesised at a reaction mixing temperature of $335{ }^{\circ} \mathrm{C}$ using balanced flow rates for the sc-water and ambient temperature metal salt feed. However, to the authors' knowledge, there are no reports on the successful direct synthesis of pure $\mathrm{VO}_{2}(\mathrm{M})$ using a continuous method.

In this study, we present the first direct continuous hydrothermal flow synthesis of $\mathrm{VO}_{2}(\mathrm{M})$ nanoparticles, which has been achieved by the modification of the CHFS apparatus and under unbalanced flow rate conditions. A vanadium(Iv) precursor solution, obtained from the reduction of vanadium(v) oxide $\left(\mathrm{V}_{2} \mathrm{O}_{5}\right)$ by oxalic acid $\left(\mathrm{H}_{2} \mathrm{C}_{2} \mathrm{O}_{4}\right)$, was used for the synthesis of the nanoparticles. The phase purity and the characteristics of the nanoparticles were investigated by X-ray absorption spectroscopy (XANES and EXAFS), X-ray diffraction, X-ray photoelectron spectroscopy and transmission electron microscopy. The thermochromic properties of the as-formed nanoparticles were determined by variable temperature UV-Vis spectroscopy. This study presents a key step towards the industrial applications of thermochromic $\mathrm{VO}_{2}$ materials.

\section{Experimental}

All chemical compounds used in the synthesis were purchased from Sigma-Aldrich.

\section{Synthesis of the precursor solution}

An aqueous $\mathrm{V}^{5+}$-containing solution (5 L) was prepared from a mixture of $181.88 \mathrm{~g}$ of $\mathrm{V}_{2} \mathrm{O}_{5}$ and $360.12 \mathrm{~g}$ oxalic acid in D.I. water (vanadium : oxalic acid, $1: 4$ ratio). This solution $(0.4 \mathrm{M})$ was stirred for $48 \mathrm{~h}$ until it was fully reduced, as evidenced by a colour change to a blue $\mathrm{V}^{4+}$-containing solution. This initial solution was diluted to $0.2 \mathrm{M}$ and used directly in the CHFS process as a precursor solution.

\section{Continuous hydrothermal flow synthesis (CHFS) of $\mathrm{VO}_{2}$ nanoparticles}

$\mathrm{VO}_{2}(\mathrm{M})$ was synthesised using a lab-scale CHFS process, which was modified from previous reports to achieve higher mixing-

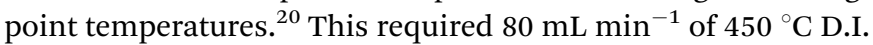
water and $10 \mathrm{~mL} \mathrm{~min}^{-1}$ combined precursor feeds to obtain a theoretical mixing point temperature of $c a .402{ }^{\circ} \mathrm{C} .{ }^{18}$ The hot water feed was provided by a Primeroyal K pump (Milton Roy, Pont Saint-Pierre, France), and the precursors were provided by two Gilson-type pumps (Gilson 305, Fig. 1, pumps G1 and G2)

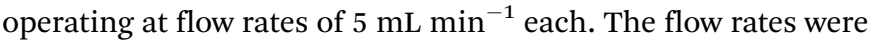
controlled using the actuators on the pumps, which were calibrated using the LabView software (LabView, National Instruments, Berkshire, UK). Both pumps G1 and G2 provided the $\mathrm{V}^{4+}$ precursor detailed in the previous paragraph. The outputs of the pumps were connected to pressure gauges (EN 837-1, WIKA Instruments Ltd, Redhill, UK), and pressure relief valves (R3A series, Swagelok) set to a relief pressure of 276 bar, a lift check valve (50 Series, Swagelok) and a non-return valve (CH Series, Swagelok) in series. The outputs of the Gilson pumps combined in a $1 / 8^{\prime \prime}$ tee-piece, which subsequently flowed into a 4-way switch valve. This switch valve was also connected to the fourth pump (P4 Milton Roy Primeroyal K pump), an exhaust pipe with a Tescom BPR and the mixing point in the reactor. The 4-way valve (7921F4Y, LAA UK Ltd, Middlesex, UK) enabled the Gilson pumps to be pressurized and depressurized in isolation from the reactor, i.e. pump P4 and the Gilson pumps could be interchanged using the valve.

During synthesis, G1 and G2 were both employed to feed the $0.2 \mathrm{M} \mathrm{V}^{4+}$ precursor solution into the reactor. The combined output of G1 and G2 flowed into a Confined Jet Mixer (CJM), where it combined with the hot water feed from $\mathrm{P} 1 .^{21}$ The theoretical mixing temperature was $402{ }^{\circ} \mathrm{C}$ for all reactions. The Reynolds number of the combined feed was $c a .14000$ and 22000 for the $1 / 8^{\prime \prime}$ and $1 / 16^{\prime \prime}$ inlet pipe reactor configurations, namely configurations $\mathrm{A}$ and $\mathrm{B}$, respectively. Configuration A was employed to synthesise the pure $\mathrm{VO}_{2}$ sample while configuration $\mathrm{B}$ was used to synthesise the $\mathrm{Nb}$-doped $\mathrm{VO}_{2}$ sample. In both cases, the extremely high Reynolds numbers resulted in very rapid and turbulent mixing between the hot water feed and the precursors. Thus, the CJM allowed complete mixing within $50 \mathrm{~ms}$ of combination, ${ }^{21}$ which occurred just beyond the supercritical 


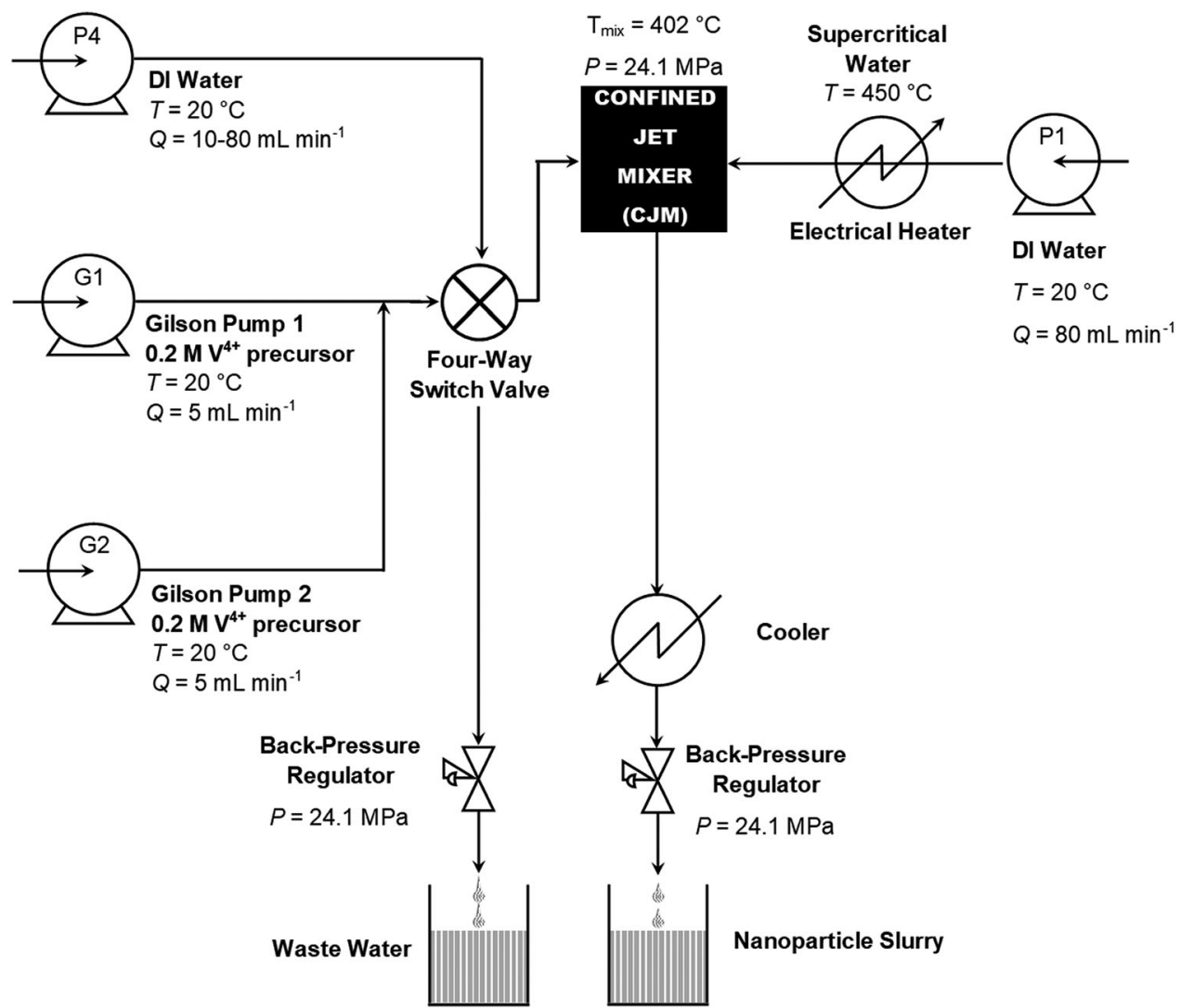

Fig. 1 Schematic diagram of the continuous hydrothermal flow synthesis (CHFS) process used in the direct synthesis of $\mathrm{VO}_{2}(\mathrm{M})$ nanoparticles.

water inlet pipe within the cross-piece as indicated in Fig. S1 (ESI $\dagger$ ). The extremely high Reynolds number resulted in very rapid and turbulent mixing between the hot water feed and the precursors, which therefore caused rapid nucleation of the $\mathrm{VO}_{2}$ product within the $1 / 4^{\prime \prime}$ outlet pipe of the CJM (Fig. S1, ESI $\dagger$ ). As the temperature of the combined feeds was $402{ }^{\circ} \mathrm{C}$, the water solvent was still in the supercritical state. The output slurry flowed through a $1.4 \mathrm{~m}$ section of the $1 / 4^{\prime \prime}$ pipe, giving a residence time of $1.0 \mathrm{~s}$, before flowing through a pipe-in-pipe counter-current cooling section to reduce the slurry temperature to $c a .40{ }^{\circ} \mathrm{C}$. The cooled product slurry exited the apparatus via a back-pressure regulator (Tescom, model 26-1762-24-194, Emerson Process Management Regulator Technologies Inc., South Lanarkshire, UK), which maintained a pressure of 240 bar in the system.

After synthesis, the supernatant was decanted from the product slurry and the concentrated paste was centrifuged at $4500 \mathrm{rpm}$ for 5 minutes. The centrifuged sludge was repeatedly resuspended in D.I. water and centrifuged until the conductivity of the supernatant was reduced below $100 \mu \mathrm{S} \mathrm{m}^{-1}$. The cleaned, wet product was placed in a freeze-drier (Virtis Genesis 35XL) and slowly heated from $-60{ }^{\circ} \mathrm{C}$ to $25{ }^{\circ} \mathrm{C}$, over $24 \mathrm{~h}$ under a vacuum of $<13 \mathrm{~Pa}$.

\section{Film analysis}

X-Ray Diffraction (XRD) was performed using a Stoe StadiP diffractometer in the transmission mode (coupled $\theta-2 \theta$ geometry), with the sample sandwiched between two plastic foil disks held together with a thin layer of silicone grease. A pre-sample Ge(111) monochromator selected Mo- $\mathrm{K}_{\alpha 1}$ radiation only $(\lambda=0.709 \AA)$ and included a $0.5 \mathrm{~mm}$ collimator restricted to $3 \mathrm{~mm}$ height. The sample was rotated in the beam, and the diffraction intensity was recorded using a Dectris Mythen $1 \mathrm{k}$ silicon strip detector covering $18^{\circ}(2 \theta)$. XRD patterns were collected in the $2 \theta$ range of $2^{\circ}$ to $40^{\circ}$ with a step size of $0.02^{\circ}$ in $2 \theta$ and were compared to the ICSD reference pattern for monoclinic $\mathrm{VO}_{2}$ (ICSD 34033).

The surface morphologies of the films were determined by Scanning Electron Microscopy (SEM) using a JEOL JSM-6700 $(3 \mathrm{kV})$.

X-ray photoelectron spectroscopy (XPS) was carried out on powder using a Thermo Scientific K-alpha spectrometer with monochromated $\mathrm{Al} \mathrm{K}_{\alpha}$ radiation, a dual beam charge compensation system and at a constant pass energy of $50 \mathrm{eV}$ (spot size $400 \mu \mathrm{m})$. Spectra were recorded from 0 to $1200 \mathrm{eV}$.

Transmission electron microscopy (TEM) images were obtained using a TEM Jeol 2100 with a $\mathrm{LaB}_{6}$ source operating at an acceleration voltage of $200 \mathrm{kV}$.

The optical transmittances were monitored using a Perkin Elmer Lambda 950 UV-Vis-NIR spectrophotometer that was equipped with a homemade heating unit. The powder was deposited onto a silica barrier (50 $\mathrm{nm} \mathrm{SiO}$ layer) float glass, supplied by Pilkington/NSG. The thermochromic properties of the deposited films were measured by recording their transmittance spectra from $2500 \mathrm{~nm}$ to $250 \mathrm{~nm}$ at two different temperatures $\left(20^{\circ} \mathrm{C}\right.$ and $\left.90{ }^{\circ} \mathrm{C}\right)$. 
To investigate the local structure of the samples, V K-edge X-ray absorption spectra were recorded on beamline B18 at diamond light source. ${ }^{22}$ B18 was equipped with a $\operatorname{Si}(111)$ dual-crystal monochromator and Pt-coated harmonic rejection mirrors. The samples were pressed into pellets, with cellulose added as the binding agent, and data were recorded in transmission mode; data for a $\mathrm{V}$ foil reference were recorded simultaneously with each sample. Commercial monoclinic vanadium dioxide was obtained from Sigma Aldrich and measured as a standard compound. Multiple spectra of each sample were averaged prior to data analysis. Data reduction and fitting were carried out using the Demeter 0.9.25 suite of programmes. ${ }^{23}$ Data fitting was performed in $R$-space.

\section{Results and discussion}

\section{Continuous hydrothermal flow synthesis and characterisation}

Continuous hydrothermal flow synthesis (CHFS) was used to produce $\mathrm{VO}_{2}(\mathrm{M})$ nanoparticles in a single step as a black powder suspension, which was cleaned and freeze-dried to yield a black powder. The vanadium(Iv) precursor solution used for the synthesis was obtained from the reduction of vanadium(v) oxide by oxalic acid according to the accepted decomposition pathway shown in eqn (R1)-(R3) $18,24,25$

$$
\begin{gathered}
\mathrm{V}_{2} \mathrm{O}_{5}(\mathrm{~s})+4 \mathrm{H}_{2} \mathrm{C}_{2} \mathrm{O}_{4}+2 \mathrm{H}_{2} \mathrm{O} \rightarrow\left[(\mathrm{VO})_{2}\left(\mathrm{C}_{2} \mathrm{O}_{4}\right)_{3}\right]^{2-}+2 \mathrm{H}_{3} \mathrm{O}^{+} \\
+2 \mathrm{CO}_{2}+4 \mathrm{H}_{2} \mathrm{O} \\
{\left[(\mathrm{VO})_{2}\left(\mathrm{C}_{2} \mathrm{O}_{4}\right)_{3}\right]^{2-}+2 \mathrm{H}_{3} \mathrm{O}^{+} \rightarrow 2 \mathrm{VOC}_{2} \mathrm{O}_{4}+\mathrm{CO}+\mathrm{CO}_{2}+3 \mathrm{H}_{2} \mathrm{O}}
\end{gathered}
$$

$$
2 \mathrm{VOC}_{2} \mathrm{O}_{4} \rightarrow \mathrm{VO}_{2}+\mathrm{CO}+\mathrm{CO}_{2}
$$

The X-ray diffraction (XRD) patterns of the undoped and Nb-doped samples both matched the $\mathrm{VO}_{2}(\mathrm{M})$ reference exclusively (PDF Card No. 01-076-0456) (Fig. 2). An additional broad feature observed in these patterns at $2 \theta \sim 5^{\circ}$ was due to the silicone-based matrix used during the sample preparation. ${ }^{26}$ This is in direct contrast to previous CHFS works, which resulted in a mixture of $\mathrm{VO}_{2}$ phases and required heat treatment to $600{ }^{\circ} \mathrm{C}$ to produce the phase-pure $\mathrm{VO}_{2}(\mathrm{M}) .{ }^{18}$ It is suggested that the higher reaction temperature (ca. $402{ }^{\circ} \mathrm{C}$ compared to $335{ }^{\circ} \mathrm{C}$ ) employed herein was necessary to drive complete conversion to the $\mathrm{VO}_{2}(\mathrm{M})$ phase in flow. The ability to manufacture $\mathrm{VO}_{2}(\mathrm{M})$ directly in a continuous process has no precedent, as the majority of synthesis methods are batch hydrothermal, and require long reaction times in the order of days. ${ }^{27,28}$ Furthermore, the precursors are relatively benign (oxalic acid is commonly used to remove rust) in comparison to these other methods (which often require chemicals with significant hazards such as hydrazine).

The undoped $\mathrm{VO}_{2}$ sample showed high crystallinity with relatively narrow peak broadening, as estimated from the FWHM values (Table 1a). In comparison with the literature pattern, a preferential orientation along the (2 20 ) plane could be observed for our samples, which is indicated by an increase in the intensity of the $\left(\begin{array}{lll}2 & 2 & 0\end{array}\right)$ peak compared with the $\left(\begin{array}{lll}0 & 1 & 1\end{array}\right)$ and

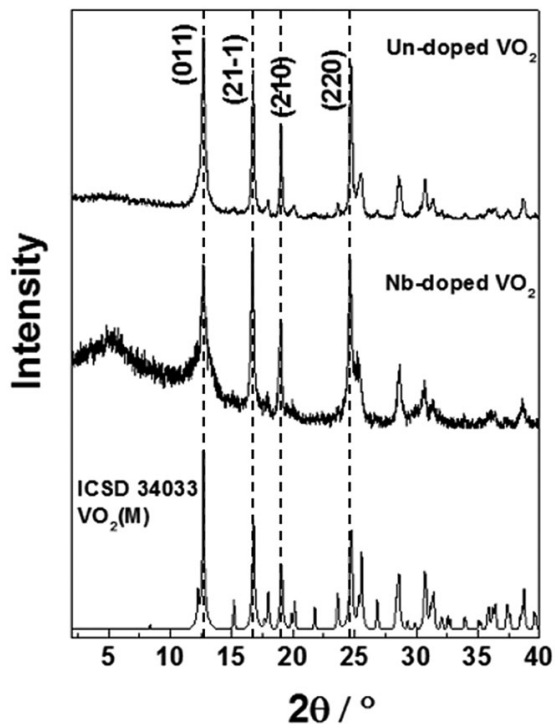

Fig. 2 XRD patterns of the $\mathrm{VO}_{2}(\mathrm{M})$ and $\mathrm{Nb}-\mathrm{VO}_{2}(\mathrm{M})$ nanoparticles synthesised by CHFS. The standard XRD pattern of monoclinic $\mathrm{VO}_{2}$ (ICSD 34033) has been included for reference.

Table 1 Crystal lattice parameters for undoped $\mathrm{VO}_{2}(\mathrm{M})$ and $\mathrm{Nb}-\mathrm{VO}_{2}(\mathrm{M})$ at room temperature

\begin{tabular}{llllll}
\hline & \multicolumn{2}{l}{ Crystal lattice parameters $(\AA)$} & & \\
\cline { 2 - 4 } Samples & $a$ & $b$ & $c$ & $\beta$ & Cell volume $V$ \\
\hline $\mathrm{VO}_{2}(\mathrm{M})$ & $9.133(1)$ & $5.674(1)$ & $4.495(1)$ & $90.69(2)$ & $232.92(6)$ \\
$\mathrm{Nb}^{-} \mathrm{VO}_{2}(\mathrm{M})$ & $9.088(2)$ & $5.784(1)$ & $4.514(1)$ & $91.47(1)$ & $237.3(1)$ \\
\hline
\end{tabular}

(2 11 1) peaks. Peak broadening is slightly higher in the case of the Nb-doped $\mathrm{VO}_{2}$ sample. This suggests the $\mathrm{Nb}$ dopant caused the reduced crystallinity, as the particle sizes of both samples were similar and therefore broadening due to the particle size effects should be approximately equal. We observe a slight change in the relative intensities of the diffraction peaks upon incorporation of the $\mathrm{Nb}$ dopant, which could be due to changes in the degree of preferred orientation of the $\mathrm{Nb}$ doped samples, or difference in the electron density between $\mathrm{Nb}^{5+}$ and $\mathrm{V}^{4+}$. The crystal lattice parameters and the monoclinic angles of the $\mathrm{VO}_{2}$ and $\mathrm{Nb}-\mathrm{VO}_{2}$ samples, as estimated from the refinement of the XRD patterns, are summarized in Table 1 . They correspond to the monoclinic $\mathrm{M} 2$ phase, where $\mathrm{VO}_{2}$ crystallizes in a centered monoclinic system with the space group $C 2 / m \cdot{ }^{29} \mathrm{VO}_{2}$ with the $\mathrm{M} 2$ phase has been previously reported in the literature for doped $\mathrm{VO}_{2}$ systems and $\mathrm{VO}_{2}$ materials obtained from stress-induced processes. ${ }^{29,30}$ This phase has attracted interest in Mott transition studies.

SEM analysis (Fig. 3) showed round-shaped particles for both $\mathrm{VO}_{2}$ and $\mathrm{Nb}-\mathrm{VO}_{2}$ samples. This morphology differs from the $\mathrm{VO}_{2}$ nanoparticles previously synthesised by CHFS, which showed rod-like particles. ${ }^{18}$ This could suggest that the higher reaction temperature used in this study $\left(402{ }^{\circ} \mathrm{C}\right)$ promoted rapid nucleation that resulted in the rounded nanoparticles. It can also be pointed out that the high uniformity of the sample indicated the ability of the CHFS process to produce consistent quality nanoparticles in a short time. 

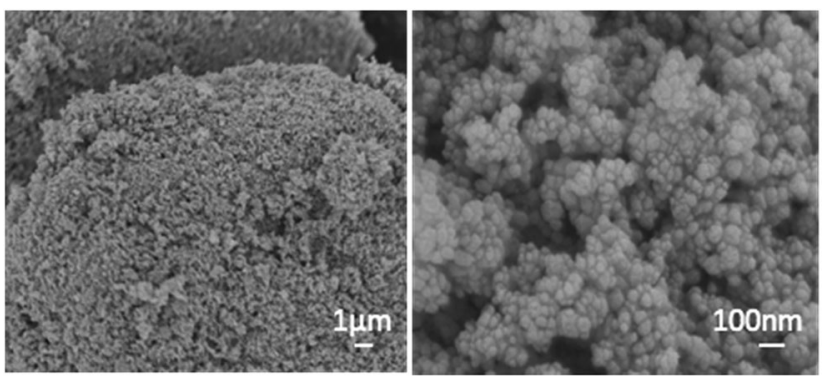

Fig. 3 SEM images of the un-doped $\mathrm{VO}_{2}(\mathrm{M})$ powder

TEM analysis of the undoped $\mathrm{VO}_{2}$ and $\mathrm{Nb}$-doped $\mathrm{VO}_{2}$ samples revealed both samples were formed of a mixture of spherical particles and hexagonal particles (Fig. 4a and b). The particle size analysis of the $\mathrm{VO}_{2}(\mathrm{M})$ and $\mathrm{Nb}-\mathrm{VO}_{2}(\mathrm{M})$ samples (50 particles per study) revealed average particle sizes of $33 \pm$ $13 \mathrm{~nm}$ and $39 \pm 13 \mathrm{~nm}$, respectively (Fig. S2, ESI $\dagger$ ). The small particle sizes observed in general were likely due to the high Reynolds number (i.e. more turbulent, rapid mixing) for both samples. The smaller particle sizes achieved herein compare extremely favourably with those made previously via CHFS, where the particle sizes were in the range of 50-200 $\mathrm{nm}$ and particle sizes below $50 \mathrm{~nm}$ were only achieved upon significant $\mathrm{Nb}$ dopant inclusion. Moreover, the post-synthesis heat-treatment required in the previous study could significantly increase the particle sizes and cause the risk of oxidation. Herein, the direct synthesis of monoclinic $\mathrm{VO}_{2}$ nanoparticles with smaller particle sizes makes this ideal for thermochromic solar control coatings. Lattice fringes, which could be assigned to the $\mathrm{VO}_{2}(\mathrm{M})$ lattice spacings, were observed in both cases (Fig. 4c and d). In addition, an organic surface coating could be observed on
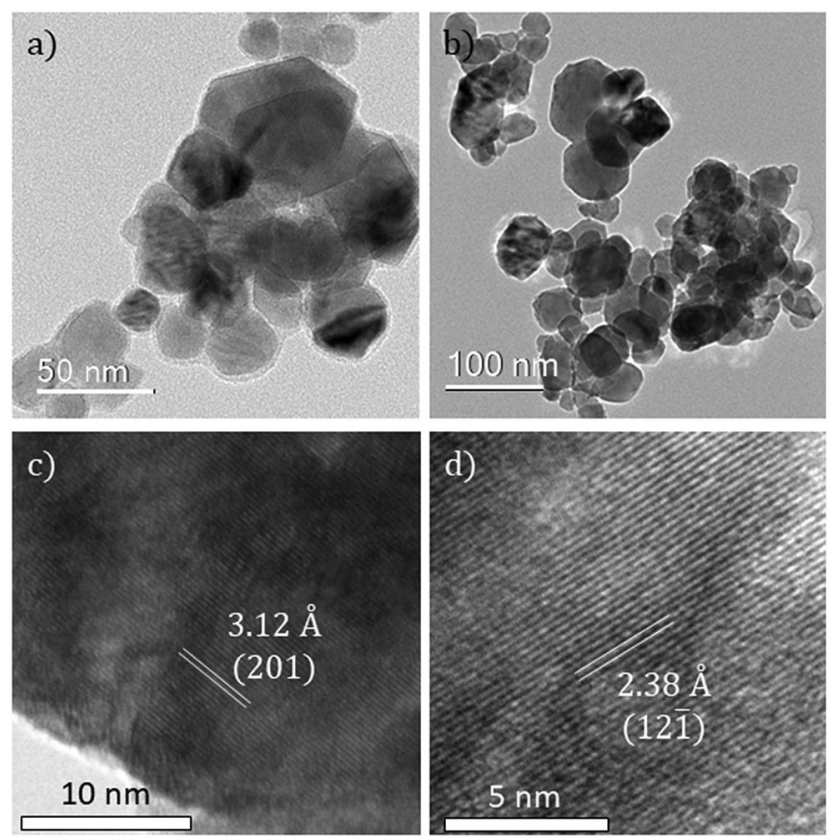

Fig. 4 TEM images of (a) undoped $\mathrm{VO}_{2}$ and (b) $\mathrm{Nb}$-doped $\mathrm{VO}_{2}$. Lattice fringes of (c) undoped $\mathrm{VO}_{2}$ and (d) $\mathrm{Nb}$-doped $\mathrm{VO}_{2}$. some particles (Fig. 4a), which visibly degraded in the beam. It is suggested that surplus oxalic acid is present in the synthesis bound to the surface of the $\mathrm{VO}_{2}$ particles.

The oxidation states of vanadium and niobium were determined by X-ray photoelectron spectroscopy (XPS). The V $2 \mathrm{p}_{3 / 2}$ core-level peak of the undoped sample could be modelled and fitted with two environments, as shown in Fig. 5. It showed the presence of two oxidation states of vanadium, $\mathrm{V}^{4+}$ and $\mathrm{V}^{5+}$, at binding energies of $514.8 \mathrm{eV}$ and $516.3 \mathrm{eV}$, respectively. This indicated that the $\mathrm{VO}_{2}$ powder is partially oxidized to $\mathrm{V}_{2} \mathrm{O}_{5}$ at the extreme surface. This is due to the powder being stored in air at room temperature and forming a $\mathrm{V}_{2} \mathrm{O}_{5}$ passivation layer. The same observation applied to the $\mathrm{Nb}$-doped powder sample. The XPS spectra are shown in Fig. 5. The atomic percentage of the $\mathrm{Nb}$ dopant in the doped sample was estimated to be $<1$ at $\%$ by modelling the $\mathrm{Nb} 3 \mathrm{~d}_{5 / 2}$ core-level peak. The $\mathrm{Nb} 3 \mathrm{~d}_{5 / 2}$ core-level peak is observed at a binding energy of $207.0 \mathrm{eV}$, which corresponds to the oxidation state of the $\mathrm{Nb}^{5+}$ ion. The low intensity of the $\mathrm{Nb} 3 \mathrm{~d}$ signal makes definitive chemical identification impossible, so it cannot be ruled out that other chemical environments of $\mathrm{Nb}$ are present. $\mathrm{Nb}$ doping did not have any significant effect on the oxidation of the $\mathrm{VO}_{2}$ powder as both samples have been shown to have the same $\mathrm{V}^{4+}: \mathrm{V}^{5+}$ ratio (ca. 33:67). This is in contrast to the previous study, where significant changes in the $\mathrm{V}^{4+}: \mathrm{V}^{5+}$ ratios were observed upon $\mathrm{Nb}$ incorporation - resulting in an increase of $\mathrm{V}^{4+}$ ions in the doped sample. ${ }^{19}$ All the above binding energies are in agreement with literature values $( \pm 0.2 \mathrm{eV}) .{ }^{31,32}$

The low levels of $\mathrm{Nb}$ detected make the influence of the dopant on the samples questionable. The low atomic percentage could be due to the precursor solution used during the synthesis. Piccirillo et $a .^{33}$ showed that in the synthesis of $\mathrm{Nb}-\mathrm{VO}_{2}$ films by chemical vapour deposition methods, a $\mathrm{Nb} / \mathrm{V}$ molar ratio threshold of $c a$. $7.5 \%$ was found in order to detect $\mathrm{Nb}$ incorporation into the films. This had also been observed with APCVD processes. ${ }^{34}$ In the current study, the precursor solution contained a $\mathrm{Nb} / \mathrm{V}$ molar ratio of $1.25 \%$ and this could explain the low dopant level in the powder. In addition, no changes in the $\mathrm{V}^{4+}: \mathrm{V}^{5+}$ ratio and the particle sizes were observed between the undoped and $\mathrm{Nb}$-doped samples unlike the previous study - suggesting that there is only a small amount of $\mathrm{Nb}$ incorporated. ${ }^{19}$ Nevertheless, the XRD patterns showed some evidence of substitution of the $\mathrm{V}^{4+}$ atoms by the $\mathrm{Nb}^{5+}$ atoms.

\section{X-ray absorption spectroscopy}

V K-edge X-ray absorption near-edge structure (XANES) spectra for these samples are shown in Fig. 6. The samples are all close in appearance to the monoclinic $\mathrm{VO}_{2}$ standard, confirming that they are phase-pure.

V K-edge extended X-ray absorption fine structure (EXAFS)/ Fourier transforms and best fits are shown in Fig. 7. These data were fitted to a theoretical structure based on ICSD $34033 ;^{35}$ the fitting model used was similar to that reported by Marini et al. ${ }^{36}$ The best fit parameters from these fits are given in Table 2. It should be noted that different $k$-space windows were used for the Fourier transforms for the different samples - this is 

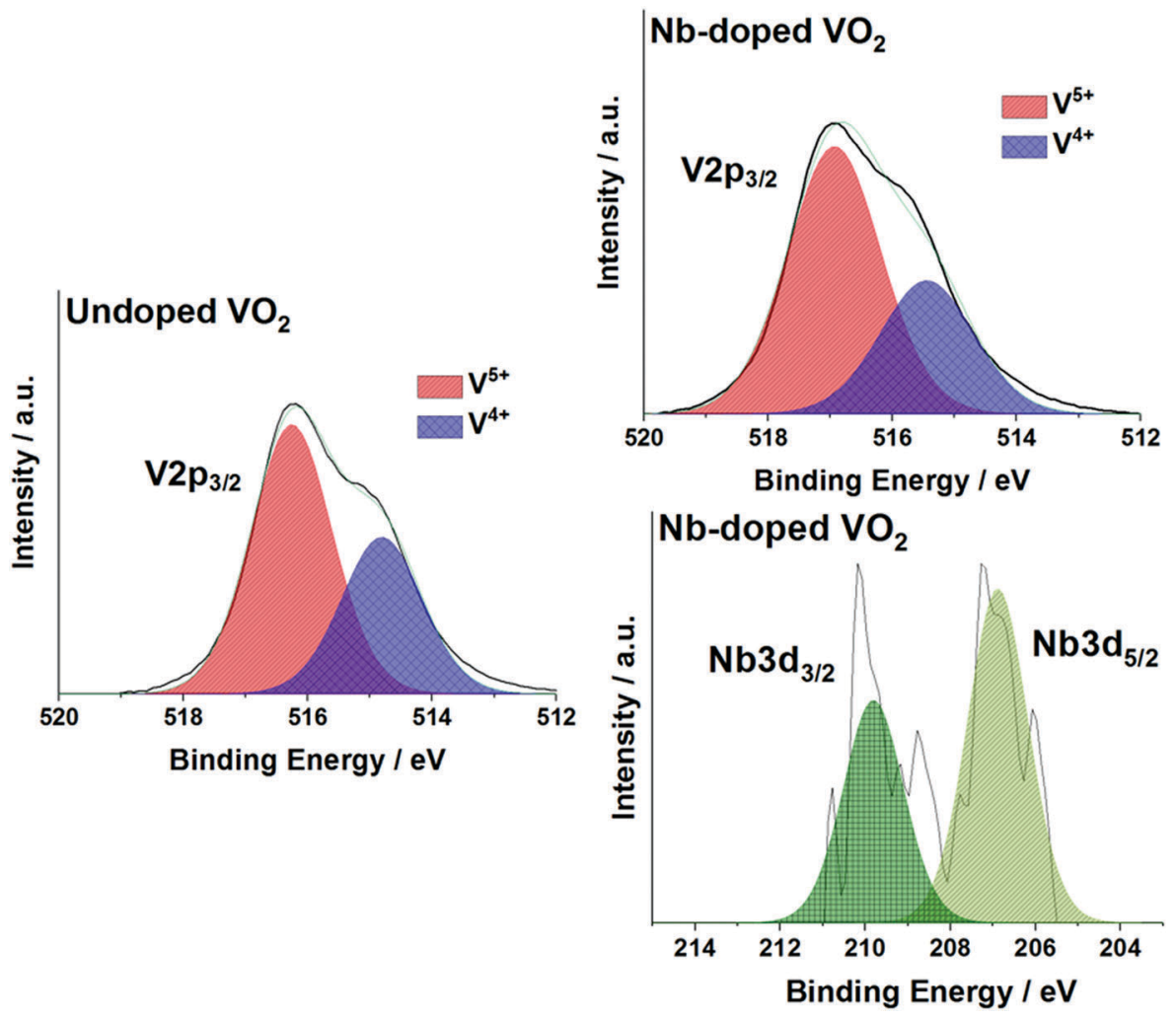

Fig. 5 X-ray photoelectron spectra (XPS) of the $\mathrm{V} 2 \mathrm{p}_{3 / 2}$ and $\mathrm{Nb} 3 \mathrm{~d}_{5 / 2}$ environments in the (a) undoped $\mathrm{VO}_{2}$ and (b) $\mathrm{Nb}-\mathrm{VO}_{2}$ samples.

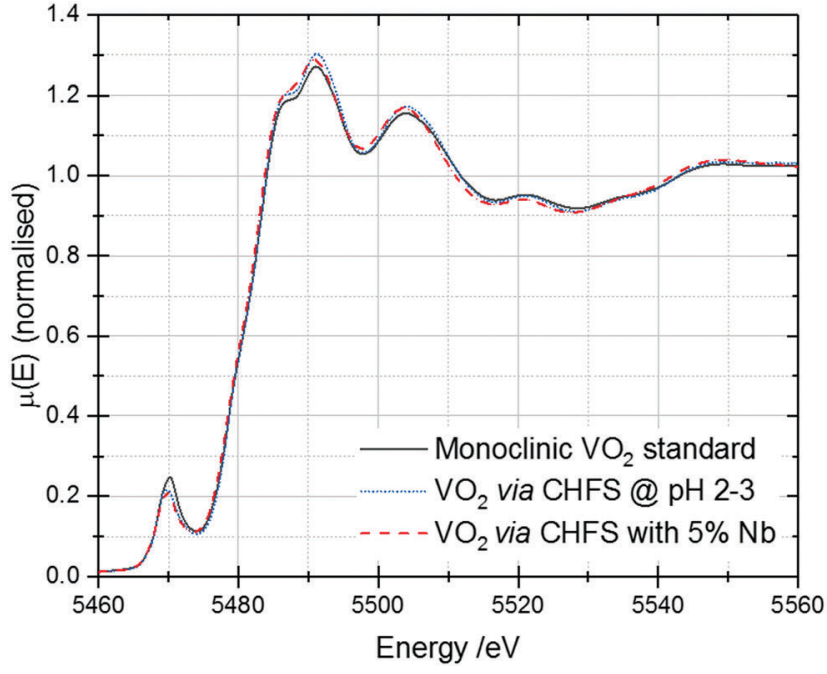

Fig. $6 \mathrm{~V}$ K-edge XANES of the $\mathrm{VO}_{2}$ and $\mathrm{Nb}-\mathrm{VO}_{2}$ samples synthesised by $\mathrm{CHFS}$. A spectrum of a commercial monoclinic $\mathrm{VO}_{2}$ standard has been included for reference.

responsible for the differences in the appearance of the samples in Fig. 7a. This was done to include the maximum possible data range in the fit, while excluding noise/high- $k$ artefacts this enables fitting of the highest possible number of parameters to the best precision.

The EXAFS of each of the samples were broadly consistent with the literature structure of monoclinic vanadium dioxide; however, the two longest $\mathrm{V}-\mathrm{O}$ distances showed a degree of expansion (without Nb: $2.37 \pm 0.04 \AA$ \& $2.42 \pm 0.04 \AA$; with $\mathrm{Nb}$ : $2.41 \pm 0.077 \AA, 2.46 \pm 0.07 \AA$; literature: $2.02 \AA$ 足 $2.06 \AA$ ), while all the other distances were (within uncertainty) in line with the literature structure. An increase in (some of) the $\mathrm{V}-\mathrm{O}$ distances while the $\mathrm{V}-\mathrm{V}$ distances remain constant suggests that there is an out-of-plane displacement of the oxygen ions, as indicated by the purple arrows in Fig. 8 .

The longer $\mathrm{V}-\mathrm{O}$ paths, which show the greatest expansion, also show increased Debye-Waller factors, indicating increased disorder in these paths. The increased disorder in the out-ofplane direction indicated in Fig. 8 would explain both the increased Debye-Waller factors and the increased average path length in this direction.

The Nb-doped sample showed a slight increase in the average distance for these $\mathrm{V}-\mathrm{O}$ bonds. This suggests that the substitution of $\mathrm{Nb}^{5+}$ into the vanadium dioxide lattice slightly increases this disorder, although this cannot be established with certainty due to the uncertainties on the fitted parameters.

Thus, the EXAFS data confirmed the monoclinic structure of these vanadium dioxide samples and confirmed that this structure is maintained after $\mathrm{Nb}$ doping. It also identified out-of-plane disorder of some of the oxygen atoms.

\section{Thermochromic properties}

The optical properties of the $\mathrm{VO}_{2}(\mathrm{M})$ nanoparticles were measured by recording their transmittance spectra from $250 \mathrm{~nm}$ to $2500 \mathrm{~nm}$ up to $90{ }^{\circ} \mathrm{C}$ (Fig. 9). All samples displayed thermochromic 
a)

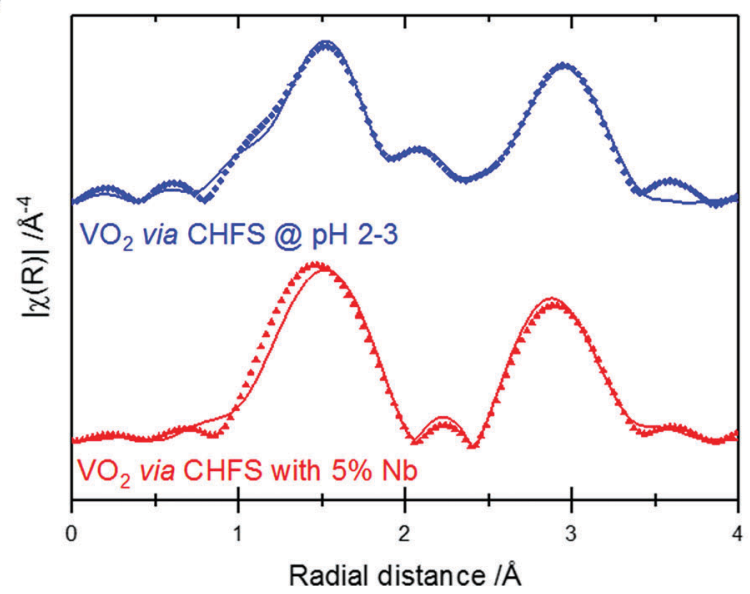

b)

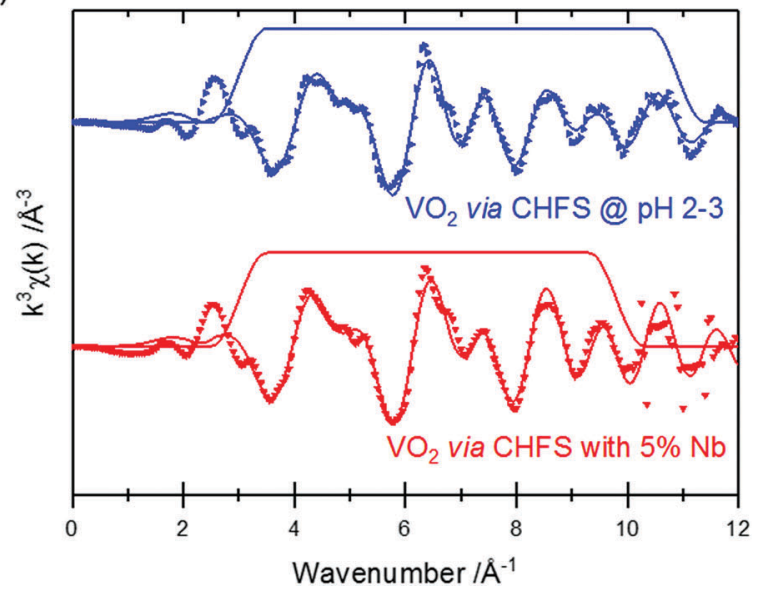

Fig. 7 V K-edge Fourier transforms (a) and EXAFS (b) of the $\mathrm{CHFS} \mathrm{VO}_{2}$ samples. Data are plotted as symbols, and fits as solid lines. The trapezoid lines in (b) indicate the Fourier transform window used.

Table 2 EXAFS best fit parameters for the $\mathrm{VO}_{2}$ samples prepared via CHFS. $\mathrm{R}$ is the half path length, $\sigma^{2}$ is the EXAFS Debye-Waller factor and $R$ factor is the crystallographic $R$-factor. All values are rounded as appropriate for their uncertainties, and uncertainties in the final digits are given in parentheses after the values. Path lengths indexed as $\delta, \varepsilon, \zeta, \theta, \mathrm{l}$ or ${ }^{\mathrm{k}}$ were refined with a common refinement parameter across all paths with the same index. Debye-Waller factors indexed as ${ }^{\eta \mu \mu}$ or ${ }^{\lambda}$ were constrained to be the same across all paths with the same index

\begin{tabular}{|c|c|c|c|c|c|}
\hline Sample & Path & Degeneracy & $R / \AA ̊ ̊$ & $\sigma^{2} / \AA^{-2}$ & $R$ factor \\
\hline \multirow{10}{*}{$\mathrm{VO}_{2}$ via $\mathrm{CHFS}$} & \multirow{4}{*}{$\mathrm{V}-\mathrm{O}$} & 1 & $1.83(5)$ & $0.009(5)$ & \multirow{10}{*}{0.008} \\
\hline & & 2 & $1.96(2)$ & & \\
\hline & & 2 & $2.37(4)^{\delta}$ & $0.016(9)^{\eta}$ & \\
\hline & & 1 & $2.42(4)^{\delta}$ & \multirow{5}{*}{$0.008(4)$} & \\
\hline & \multirow[t]{6}{*}{$\mathrm{V}-\mathrm{V}$} & 1 & 2.61(3) & & \\
\hline & & 1 & $3.17(9)$ & & \\
\hline & & 2 & $3.41(9)^{\varepsilon}$ & & \\
\hline & & 2 & $3.49(9)^{\varepsilon}$ & & \\
\hline & & 2 & $3.4(2)^{\zeta}$ & \multirow[t]{2}{*}{$0.016(9)^{\eta}$} & \\
\hline & & 2 & $3.5(2)^{5}$ & & \\
\hline \multirow[t]{10}{*}{$\mathrm{Nb}-\mathrm{VO}_{2}$ via $\mathrm{CHFS}$} & \multirow[t]{4}{*}{$\mathrm{V}-\mathrm{O}$} & 1 & $1.85(1)^{\theta}$ & \multirow[t]{2}{*}{$0.0025(9)^{\lambda}$} & \multirow[t]{10}{*}{0.010} \\
\hline & & 2 & $1.97(1)^{\theta}$ & & \\
\hline & & 2 & $2.41(7)^{1}$ & $0.013(4)$ & \\
\hline & & 1 & $2.46(7)^{i}$ & & \\
\hline & \multirow[t]{6}{*}{$\mathrm{V}-\mathrm{V}$} & 1 & $2.7(2)$ & \multirow[t]{2}{*}{$0.02(1)^{\mu}$} & \\
\hline & & 1 & $3.3(4)$ & & \\
\hline & & 2 & $3.42(2)^{\kappa}$ & \multirow[t]{2}{*}{$0.0025(9)^{\lambda}$} & \\
\hline & & 2 & $3.50(2)^{\kappa}$ & & \\
\hline & & 2 & $3.59(2)^{\kappa}$ & \multirow[t]{2}{*}{$0.013(4)^{\mu}$} & \\
\hline & & 2 & $3.66(2)^{\kappa}$ & & \\
\hline
\end{tabular}

behaviour with a reversible switch around $c a .68{ }^{\circ} \mathrm{C}$ - corresponding to the typical transition temperature expected for undoped $\mathrm{VO}_{2}$. The luminous and solar transmittance $\left(T_{\text {lum }}\right.$ and $\left.T_{\mathrm{sol}}\right)$ were estimated based on the measured spectra using the equation below (Table 3):

$$
T_{\text {lum }, \text { sol }}^{\sigma} \equiv \frac{\int \Phi_{\text {lum }, \text { sol }} T^{\sigma}(\lambda) \mathrm{d} \lambda}{\int \Phi_{\text {lum }, \text { sol }}(\lambda) \mathrm{d} \lambda}
$$

where $\lambda$ is the wavelength of light, $\phi_{\text {lum }}$ is the solar irradiance weighted to the sensitivity of the human eye, $\phi_{\text {sol }}$ is the weighted solar irradiance spectrum, and $T^{\sigma}$ is the transmission

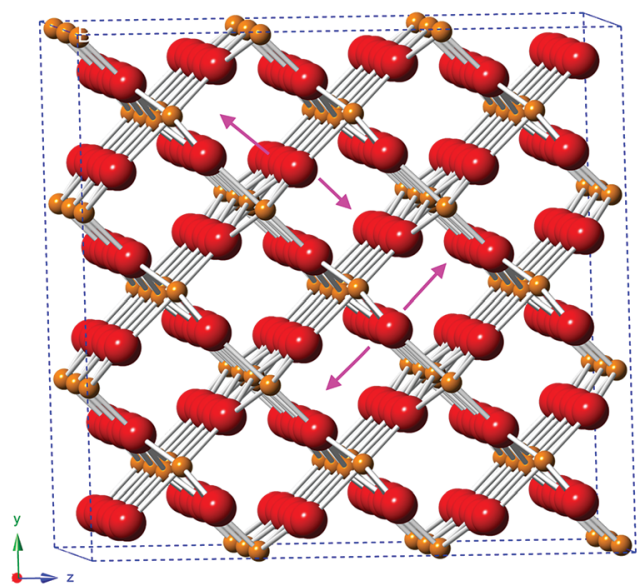

Fig. 8 Structure of monoclinic $\mathrm{VO}_{2}$, based on ICSD 34033, indicating the direction of the proposed out-of-plane oxygen displacement (purple arrows). $\mathrm{O}^{2-}$ : red; $\mathrm{V}^{4+}$ : orange.

of the $\mathrm{VO}_{2}$ thin film in either the hot state or the cold state. From the above equation, the solar modulation $\left(\Delta T_{\text {sol }}\right)$ can be deduced from the difference between the solar transmittance in the cold and hot states:

$$
\Delta T_{\text {sol }}=T_{\text {sol }}\left(25^{\circ} \mathrm{C}\right)-T_{\text {sol }}\left(90^{\circ} \mathrm{C}\right)
$$

The modulation in the infrared region $\left(\Delta T_{\mathrm{IR}}\right)$ was also estimated from eqn (2) as it only takes into account the nearinfrared region (750 to $2500 \mathrm{~nm}$ ) of the measured spectra, which is specific for the thermochromic functionality expected.

The undoped $\mathrm{VO}_{2}$ powder showed a $\Delta T_{\text {sol }}$ of $3.8 \%$, which is in line with those of the un-doped $\mathrm{VO}_{2}$ materials synthesised by other methods such as magnetron sputtering or APCVD. ${ }^{37-39}$ The powder exhibited a good efficiency for modulating infrared radiation with a $\Delta T_{\mathrm{IR}}$ of $7 \%$, however, it displayed a low visible light transmittance $\left(T_{\text {lum }}=14 \%\right)$.

Several studies showed that doping $\mathrm{VO}_{2}$ samples with niobium is usually accompanied by a decrease of the visible 


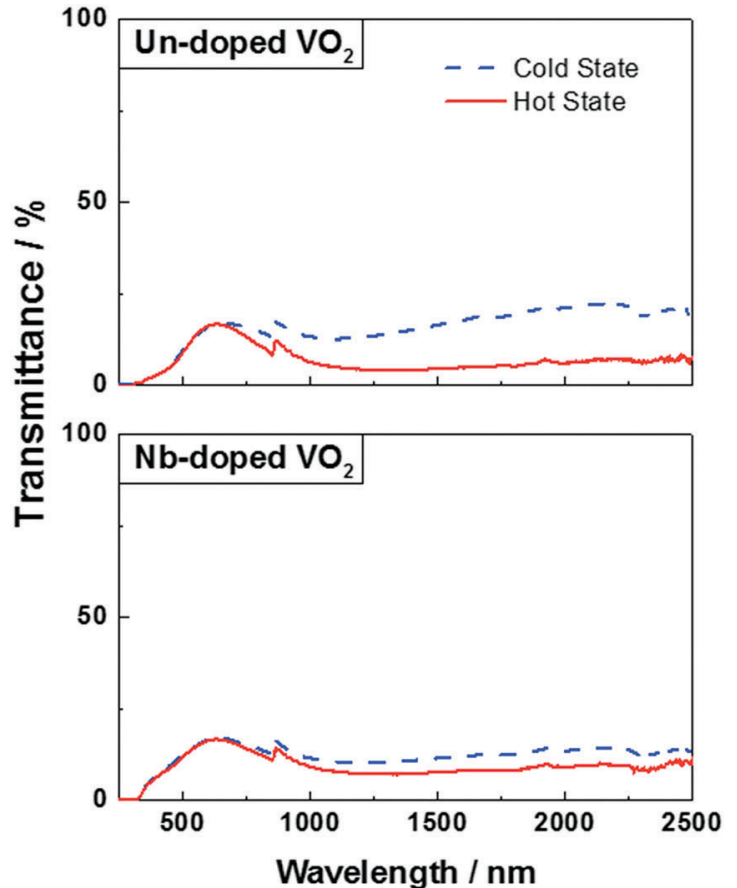

Fig. 9 UV-Vis spectra of un-doped $\mathrm{VO}_{2}$ (top) and $\mathrm{Nb}$-doped $\mathrm{VO}_{2}$ (bottom) at $20{ }^{\circ} \mathrm{C}$ (blue dashed line) and $90{ }^{\circ} \mathrm{C}$ (continuous red line).

Table 3 Visible light transmittance $T_{\text {lum }}$ in the cold and hot states, solar modulation $\Delta T_{\text {sol }}$ and solar modulation in the NIR region $\Delta T_{\mathrm{IR}}$ for the un-doped $\mathrm{VO}_{2}$ and $\mathrm{Nb}$-doped $\mathrm{VO}_{2}$ samples

\begin{tabular}{llllll}
\hline & $T_{\text {lum }}(\%)$ & & & \\
\cline { 2 - 3 } Samples & Cold state & Hot state & & $\Delta T_{\text {sol }}(\%)$ & $\Delta T_{\text {IR }}(\%)$ \\
\hline Un-doped $\mathrm{VO}_{2}$ & 14 & 14 & 3.8 & 7 \\
Nb-doped $\mathrm{VO}_{2}$ & 15 & 15 & 1.5 & 2.4 \\
\hline
\end{tabular}

light transmittance $T_{\text {lum }}$ and a MST reduction. ${ }^{40-42}$ Both samples, however, have a similar $T_{\text {lum }}$ of $15 \%$ and $14 \%$ for the doped and un-doped samples, respectively. Moreover, the transition temperature (MST) of the doped sample is around ca. $68{ }^{\circ} \mathrm{C}$, which is the MST observed for a typical undoped $\mathrm{VO}_{2}$ material. This can be explained by the very low at\% of niobium present in the powder - the atomic percentage is too low for observing any effect on the optical properties. On the other hand, Table 3 shows a poor ability of the Nb-doped sample to modulate infrared radiation, which can be seen by a drop in the $\Delta T_{\text {sol }}(1.5 \%)$ and $\Delta T_{\mathrm{IR}}(2.4 \%)$ when compared to the undoped powder. This is most likely due to the lower crystallinity of the doped material. It has been shown that a poor crystallinity of the $\mathrm{VO}_{2}$ samples resulted in a low solar modulation. ${ }^{39}$ Furthermore, both samples have been shown to have the same $\mathrm{V}^{4+}: \mathrm{V}^{5+}$ ratio and similar average particle sizes.

As a result, the undoped $\mathrm{VO}_{2}$ nanoparticles synthesised by CHFS showed good thermochromic properties. Both samples have been revealed to have a low luminous transmittance, which could be caused by the sample preparation for UV-Vis measurements. The small average particle sizes of the samples suggest that a good dispersion of the NPs in a host could significantly increase the $T_{\text {lum }}$. Doping with niobium did not seem to have any impact on the luminous transmittance and the MST. Only a change in the $\Delta T_{\text {sol }}$ has been observed and is most likely a result of the differing degrees of crystallinity.

\section{Conclusions}

Pure monoclinic $\mathrm{VO}_{2}$ nanoparticles (undoped and doped with niobium) were successfully synthesised by CHFS at a mixer reaction temperature of $c a .400{ }^{\circ} \mathrm{C}$. The synthesis was direct and no post-synthesis heat-treatment of the samples was required. The vanadium(Iv) precursor solution was immediately converted into a $\mathrm{VO}_{2}(\mathrm{M})$ nanoparticle slurry in the process. The undoped $\mathrm{VO}_{2}$ powder possessed good thermochromic properties, a $\Delta T_{\text {sol }}$ of $3.8 \%$ and a $\Delta T_{\mathrm{IR}}$ of $7 \%$, but a low visible light transmittance, which could be attributed to the sample preparation. The Nb-doped sample was synthesised using a $\mathrm{Nb} / \mathrm{V}$ solution with a molar ratio of $1.25 \%$. The XRD patterns and XANES and EXAFS analyses highlighted some evidence of $\mathrm{Nb}^{5+}$ substitutions into the $\mathrm{VO}_{2}$ lattice, suggesting that the $\mathrm{Nb}$ dopant induced a relatively poor $\mathrm{VO}_{2}$ crystallinity. Nevertheless, the molar ratio of the $\mathrm{Nb} / \mathrm{V}$ solution was too low to have any significant effect on the MST and the optical properties of the sample, or for definitive conclusions on the nature of the $\mathrm{Nb}$ in the sample to be ascertained. Despite the low luminous transmittance for both samples, the TEM images showed small particle sizes (in the range of 30 to $40 \mathrm{~nm}$ ), which could lead to a significant increase of the $T_{\text {lum }}$ if the particles are well dispersed in a host in the future.

\section{Conflicts of interest}

There are no conflicts to declare.

\section{Acknowledgements}

This study was funded by the chemistry department of the UCL and the Engineering and Physical Sciences Research Council, EPSRC (EP/M003353/1 intelligent coatings for energy efficient glazing, ICE glazing). Diamond is acknowledged for access to B18 under proposal SP17147-1. IDJ is funded via the JUICED energy hub (EP/R023662/1). CJC and MJP acknowledge EPSRC grant EP/L017709/1.

\section{References}

1 M. Lübke, N. Ding, M. J. Powell, D. J. L. Brett, P. R. Shearing, Z. Liu and J. A. Darr, Electrochem. Commun., 2016, 64, 56-60.

2 L. Jiang, Y. Qu, Z. Ren, P. Yu, D. Zhao, W. Zhou, L. Wang and H. Fu, ACS Appl. Mater. Interfaces, 2015, 7, 1595-1601.

3 Y. Qin, G. Fan, K. Liu and M. Hu, Sens. Actuators, B, 2014, 190, 141-148.

4 J. Zhou, Y. Gao, Z. Zhang, H. Luo, C. Cao, Z. Chen, L. Dai and X. Liu, Sci. Rep., 2013, 24, 1-5. 
5 G. Sun, X. Cao, X. Gao, S. Long, M. Liang and P. Jin, Appl. Phys. Lett., 2016, 109, 143903.

6 Z. Zhang, Y. Gao, Z. Chen, J. Du, C. Cao, L. Kang and H. Luo, Langmuir, 2010, 26, 10738-10744.

7 C. G. Granqvist, S. Green, G. A. Niklasson, N. R. Mlyuka, S. von Kræmer and P. Georén, Thin Solid Films, 2010, 518, 3046-3053.

8 D. Vernardou, M. E. Pemble and D. W. Sheel, Chem. Vap. Deposition, 2006, 12, 263-274.

9 S. Y. Li, G. A. Niklasson and C. G. Granqvist, J. Appl. Phys., 2011, 109, 1-6.

10 S. Y. Li, G. A. Niklasson and C. G. Granqvist, J. Appl. Phys., 2010, 108, 63525.

11 C. G. Granqvist, Mater Today: Proc., 2016, 3, S2-S11.

12 K. Laaksonen, S. Y. Li, S. R. Puisto, N. K. J. Rostedt, T. Ala-Nissila, C. G. Granqvist, R. M. Nieminen and G. A. Niklasson, Sol. Energy Mater. Sol. Cells, 2014, 130, 132-137.

13 N. Wang, Q. Sheng, P. Lin, S. Magdassi and Y. Long, J. Alloys Compd., 2017, 711, 222-228.

14 J. Zhu, A. Huang, K. Tong, S. Ji, S. Bao, X. Cao and P. Jin, ACS Appl. Mater. Interfaces, 2016, 8, 29742-29748.

15 J. A. Darr, J. Zhang, N. M. Makwana and X. Weng, Chem. Rev., 2017, 117, 11125-11238.

16 M. Lübke, I. Johnson, N. M. Makwana, D. Brett, P. Shearing, Z. Liu and J. A. Darr, J. Power Sources, 2015, 294, 94-102.

17 T. Adschiri, K. Kanazawa and K. Arai, J. Am. Ceram. Soc., 1992, 22, 1019-1022.

18 M. J. Powell, P. Marchand, C. J. Denis, J. C. Bear, J. A. Darr and I. P. Parkin, Nanoscale, 2015, 7, 18686-18693.

19 R. Quesada-Cabrera, M. J. Powell, P. Marchand, C. J. Denis, J. A. Maggio, F. Di Darr and I. P. Parkin, J. Nanosci. Nanotechnol., 2016, 16, 10104-10111.

20 R. I. Gruar, C. J. Tighe and J. A. Darr, Ind. Eng. Chem. Res., 2013, 52, 5270-5281.

21 I. D. Johnson, M. Loveridge, R. Bhagat and J. A. Darr, ACS Comb. Sci., 2016, 18, 665-672.

22 A. J. Dent, G. Cibin, S. Ramos, A. D. Smith, S. M. Scott, L. Varandas, R. M. Pearson, N. A. Krumpa, C. P. Jones and P. E. Robbins, J. Phys. Conf. Ser., 2009, 190, 12039.

23 B. Ravel and M. Newville, J. Synchrotron Radiat., 2005, 12, 537-541.
24 D. N. Sathyanarayana and C. C. Patel, J. Inorg. Nucl. Chem., 1965, 27, 297-302.

25 D. N. Sathyanarayana and C. C. Patel, J. Inorg. Nucl. Chem., 1966, 28, 2277-2283.

26 T. G. Ros, M. K. Van Der Lee, A. J. Van Dillen, J. W. Geus and D. C. Koningsberger, J. Mol. Catal. A: Chem., 2002, 186, 13-24.

27 J. H. Son, J. Wei, D. Cobden, G. Cao and Y. Xia, Chem. Mater., 2010, 22, 3043-3050.

28 J. Zhou, Y. Gao, X. Liu, Z. Chen, L. Dai, C. Cao, H. Luo, M. Kanahira, C. Sun and L. Yan, Phys. Chem. Chem. Phys., 2013, 15, 7505.

29 M. Marezio, D. B. McWhan, J. P. Remeika and P. D. Dernier, Phys. Rev. B: Solid State, 1972, 5, 2541-2551.

30 K. Okimura, T. Watanabe and J. Sakai, J. Appl. Phys., 2012, 111, 1-7.

31 G. Silversmit, D. Depla, H. Poelman, G. B. Marin and R. De Gryse, J. Electron Spectrosc. Relat. Phenom., 2004, 135, 167-175.

32 P. E. Sobol and J. Chastain, Handbook of X-ray Photoelectron Spectroscopy, 1993.

33 C. Piccirillo, R. Binions and I. P. Parkin, Eur. J. Inorg. Chem., 2007, 4050-4055.

34 T. D. Manning, I. P. Parkin, M. E. Pemble, D. Sheel and D. Vernardou, Chem. Mater., 2004, 16, 744-749.

35 J. M. Longo and P. Kierkegaard, Acta Chem. Scand., 1970, 24, 420-426.

36 C. Marini, S. Pascarelli, O. Mathon, B. Joseph, L. Malavasi and P. Postorino, EPL, 2013, 102, 66004.

37 N. R. Mlyuka, G. A. Niklasson and C. G. Granqvist, Sol. Energy Mater. Sol. Cells, 2009, 93, 1685-1687.

38 M. J. Powell, R. Quesada-Cabrera, A. Taylor, D. Teixeira, I. Papakonstantinou, R. G. Palgrave, G. Sankar and I. P. Parkin, Chem. Mater., 2016, 28, 1369-1376.

39 D. Malarde, M. J. Powell, R. Quesada-cabrera, R. L. Wilson, C. J. Carmalt, G. Sankar, I. P. Parkin and R. G. Palgrave, ACS Omega, 2017, 2, 1040-1046.

40 Y. Li, Y. Liu, J. Liu and L. Ren, J. Mater. Sci.: Mater. Electron., 2016, 27, 4981-4987.

41 H. M. Pinto, J. Correia, R. Binions, C. Piccirillo, I. P. Parkin and V. Teixeira, Mater. Sci. Forum, 2008, 587, 640-644.

42 C. Batista, J. Carneiro, R. M. Ribeiro and V. Teixeira, J. Nanosci. Nanotechnol., 2011, 11, 9042-9045. 